ican botanists. The failure to recognize the basic principle of generic types, and the absurd recommendation to make exceptions from the rules adopted in the case of over 400 generic names, make it morally certain that these rules will not be final and will not settle the vexed question of nomenclature. It also seems morally certain that these rules will not be even temporarily accepted by the majority of American systematic botanists. I have read Dr. Britton's paper carefully in the hope that I could find either in or between the lines some hint of the position that he, as chairman of the American Nomenclature "Commission, intends to take with reference to these really extraordinary rules. I confess, however, that his purpose has been well veiled. The question is one of such immediate interest and importance in view of the publication of the new 'Flora of North America' that I venture to ask for an expression of his views in your columns as to what shall be done next. For my own part I am free to express the opinion that any attempt to conform to the Vienna rules would be most unfortunate and would only serve to postpone still farther the muchdesired attainment of practical stability in the use of plant names.

Fortunately for those of us who are interested in the lower cryptogams, the congress has saved us from the necessity of breaking its rules. If it had confessed its incapacity in regard to the higher plants as.well, the situation would be far simpler.

Santiago de las Vegas, Cuba, F. S. EARLE. September 7, 1905.

\section{'CLON' VERSUS 'CLONE.'}

I RECUR to this subject merely to correct the misunderstanding under which Professor Eastman labors, as shown in his recent communication to ScIence (XXII., p. 206). In my note setting forth the reasons for preferring the spelling clone, I did not state the chief fact on which the argument was based, inasmuch as I assumed that any one interested in the subject would undoubtedly consult $\mathrm{Mr}$. Webber's article, ${ }^{1}$ in which the word was orig-

${ }^{1}$ ScIence, XVIII., 501-503, 1903. inally published. Let it be clearly understood, therefore, that viewed in the abstract, one spelling is as good as another, and Professor Eastman's reasons for preferring clon, would be quite cogent if it were not for the fact that Mr. Webber expressly states that the word is to be pronounced with the long sound of $o$. This being the case, I think no one will venture to dispute the point I have already made, that by the requirements of English speech it must be written clone or treated purely as a transliteration from the Greek and written clon (preferably klōn). Every one of the examples adduced by Professor Eastman (eon, pæon, autochthon, halcyon) affords proof of this, as they are all pronounced with a short $o$ ! It is quite true, as Professor Eastman states, that 'linguistic usage does not require that loan words and derivatives from other languages should always preserve the same vowel quantities.' But it does require that if the vowel quantity is to be definitely indicated in pronunciation, as Mr. Webber desires in the case of this word, it must be also indicated by the orthography or by some graphic mark of quantity. Hence the word must be treated lexicographically as either clōn or clone. If written simply clon, everyone would be justified in pronouncing it clón.

SPRingField, Mass.

$$
\text { Charles Louis Pollard. }
$$

\section{SPECIAL ARTICLES.}

A DIAGRAM OR CHART FOR FINDING THE SUN'S AZIMUTH.

In Science for July 24, 1903, under the title 'On Uses of a Drawing Board and Scales in Trigonometry and Navigation,' I have briefly described such simple apparatus as seemed to be most serviceable in the solution of spherical triangles. What is written here may be regarded as a continuation of that article, because the apparatus there described can be used in place of the azimuth diagram and in ways quite analogous to those here outlined.

Given two sides of a spherical triangle and the included angle, to find one of the remaining angles without first finding the side op- 